was evaluated in relation to blood lead levels and behavior, particularly pica. Children with blood levels less than 30 $\mathrm{mcg} / \mathrm{dl}$ were compared with a group having blood levels greater than $30 \mathrm{mcg} / \mathrm{dl}$. The study verified the positive association between blood lead levels and pica, an association recognized for many years. Decreased calcium intake and three other calcium measures were not related to blood lead levels and calcium intake was not associated with pica scores. (Laraque D et al. Blood lead, calcium status and behavior in preschool children. AJDC Feb 1990; 144:186-189). Pica has been emphasized as a common prelude to plumbism (Millichap JG et al. Lead paint: A hazard to children. Lancet $1952 ; 2: 360$ ) and should prompt the early diagnosis of lead exposure and prevention of neurobehavioral deficits. The identification of children with lead poisoning in need of chelation is possible using unstimulated urinary lead excretion without the necessity of the CaNa ${ }_{2}$ EDTA provocative test. (Berger $O G$ et al. Using unstimulated urinary lead excretion to assess the need for chelation in the treatment of lead poisoning. J Pediatr $1990 ; 116: 46-51)$.

\title{
POLYCHLORINATED BIPHENYLS (PCBS) AND COCNITIVE DEFICITS
}

The effects of prenatal exposure to polychlorinated biphenyls (PCBs) and related contaminants on the aNS function of infants born to women who had consumed Lake Michigan sports fish have been investigated in 236 children previously evaluated for PCB-related deficits in infancy and reassessed at four years of age in the Psychology Department, Wayne State University, Detroit, MI and the Michigan Department of Public Health, Lansing, MI. Prenatal exposure, indicated by umbilical cord serum PCB levels, was associated with poorer short term memory function on both verbal and quantitative tests and the adverse effects were dose dependent and not attributed to other variables. Exposure from nursing was unrelated to cognitive performance. The study demonstrates continuation of toxic effects through early childhood. (Jacobson JL et al. Effects of in utero exposure to polychlorinated biphenyls and related contaminants on cognitive functioning in young children. J Pediatr Jan 1990; $116: 38-45$ ).

COMMENT. Polychlorinated biphenyls were once used in industrial products and were banned in the United States in 1970. Residues persist in air, soil, water and sediments in lakes and can be detected in residents of industrialized countries. PCB levels are unusually high in sports fish from Lake Michigan and transplacental exposure to PCBs has been documented.

\section{PARTIAL BIOTINIDASE DEFICIENCY}

The symptams, biochemical features and inheritance pattern of partial biotinidase deficiency have been studied at the Departments of Human Genetics and Pediatrics, Medical College of Virginia, Richmond, 
VA; the State Laboratory Institute, Massachusetts Department of Public Health; Massachusetts General Hospital, Boston; the Lincoln Clinic, NB; and the Division of Human Genetics, University of Maryland School of Medicine, Baltimore. Twelve boys and four girls identified by newborn screening had partial biotinidase deficiency, defined as $10 \%$ to $30 \%$ of the mean normal activity. Three siblings of these children also had partial deficiency. Fourteen children ascertained by neonatal screening had profound biotinidase deficiency (less than 108 mean normal activity). Two siblings with profound deficiency were found among older siblings of these children. In 24 children with symptoms biotinidase activity levels were less than $10 \%$ of the mean normal level. All children with partial deficiency were healthy at the time of diagnosis. One child not treated initially with biotin later developed hypotonia, hair loss and skin rash which resolved with biotin therapy. Delayed development of symptams in some cases may depend on the interaction of reduced biotinidase activity with other factors. e.g. availability of exogenous biotin and alterations in metabolic demand for the vitamin. The need for biotin supplementation may be increased at times of infection and stress. (McVoy JRS, Wolf B et al. Partial biotinidase deficiency: Clinical and biochemical features. $J$ Pediatr Jan $1990 ; 116: 78-83)$.

COMMENT. Biotin responsive late onset multiple carboxylase deficiency is an autosamal recessive inherited disorder manifested by seizures, alopecia, skin rash, hypotonia, ataxia, hearing loss, and developmental delay. Lactic acidosis and organic aciduria are often present and if untreated the symptams become progressively worse and cama and death may occur. Symptams of biotinidase deficiency resolve rapidly after treatment with biotin 5-10 mg daily orally, but neurologic damage may be irreversible. Early diagnosis and treatment of partial biotinidase deficiency may prevent the development of potentially serious consequences.

\section{DEGENERATIVE DISORDERS}

\section{ATAXIA-TEIANGIECTASIA}

The proportion of T-cell antigen receptors in ten patients with ataxia-telangiectasia were compared with normal subjects and patients with other immune deficits at the Departments of Clinical Immunology and Pediatrics, University of Rome, "la Sapienza" Rome, Italy. An increased ratio of ganma/delta bearing to alpha/beta bearing T-cells in ataxia-telangiectasia may reflect both a recombinational defect that interferes with $\mathrm{T}$-cell and $\mathrm{B}-\mathrm{cell}$ gene rearrangements and an inability to repair damage to the DNA. The criteria for the diagnosis of ataxia-telangiectasia included early cerebellar ataxia, chromosamal instability, and raised alpha fetoprotein levels. There were six boys and four girls ranging in age from 2-18 years. The diagnos is was confirmed by cytogenetic analysis which showed the typical increase in 